\title{
MODEL PEMANFAATAN ATAS TANAH TERLANTAR DARI HAK GUNA USAHA DIKAITKAN DENGAN PENGEMBANGAN USAHA PONDOK PESANTREN DI KAWASAN BOPUNJUR
}

\section{MODEL OF ABANDONED LAND UTILIZATION FROM CULTIVATION RIGHTS TITEL IN RELATION TO THE DEVELOPMENT OF BUSINESS IN ISLAMIC BOARDING SCHOOL AROUND BOPUNJUR AREAS}

\author{
Rizal Syamsul Maarif dan \\ Martin Roestamy
}

\author{
Magister Hukum Sekolah Pascasarjana, \\ Universitas Djuanda Bogor. \\ Korespondensi : Rizal Syamsul Ma'arif, Tel. \\ e-mail : rizal.syamsul.m@unida.ac.id
}

Jurnal Living Law, Vol. 13, No. 1, 2021 hlm. 63-71

\begin{abstract}
The objectives of this study are 1) To identify and analyze the concept and politics of enclaving abandoned land ex-land use rights (HGU) in Indonesia 2) To find out and conduct legal analysis regarding the development of an enclaving model of abandoned land ex-land use rights (HGU) of PTPN VIII for the development of a Pondok Pesantren business in the Bopunjur area. The research method used in this research is normative juridical analysis research with a qualitative approach combining secondary legal materials with primary legal materials so as to produce a fact analysis that occurs in the field. The results of this study are: 1) the concept and politics of enclaving on ex-plantation and agricultural land in the Bopunjur area can be utilized as a business development for a Pondok Pesantren, taking into account the 3-year period the land is not suitable for its purpose. And even tend to be neglected or have experienced several cultivated operations. 2) an enclaving development model for abandoned PTPN VIII land, namely by following the asset empowerment cooperation procedure for 5 years, on the way it can be upgraded to a right of use certificate and for 3 consecutive years you can request enclav to the Provincial BPN because Bopunjur is a direct area under the auspices of the Provincial BPN by observing the principle of benefiting the abandoned land into productive activities
\end{abstract}

Keywords : Enclaving Model Development, Utilization Principles, Abandoned Land 


\section{PENDAHULUAN}

Bagi bangsa Indonesia, tanah adalah sesuatu yang bersifat asasi dan merupakan unsur yang sangat rentan dalam kehidupan sosial dan kemasyarakatan, tanah sesuatu yang dianggap sakral, urusan leluhur dan turun temurun, menyangkut harga diri atau marwah satu keluarga dalam kehidupan masyarakat berbangsa dan bernegara. ${ }^{1}$

Hal itu tertuang jelas pada konstitusi Negara yakni Pasal 33 ayat (3) UUD 1945 menyebutkan bahwa "bumi. Air dan kekayaan alam yang terkandung di dalamnya dikuasai oleh negara dan dipergunakan untuk sebesar-besarnya kemakmuran rakyat"

Maka dari itu dalam penjabaran selanjutnya pada Pasal 33 ayat (4) memungkinkan penggunaan tanah yang dikuasai negara tersebut harus diperuntukan menggunakan asas efisiensi yang berkeadilan, bermakna bahwa tanahtanah yang dikuasakan kepada pemegang hak harus memberikan manfaat secara benar sesuai dengan peruntukan tanah tersebut.

Secara normatif, jika sejatinya tujuan untuk pemanfaatan tanah untuk sebesarbesarnya bagi kemakmuran rakyat maka akibat hukumnya ialah tanah sebagai sumber daya alam harus dijaga dan dilestarikan jangan sampai dirusak apalagi diterlantarkan karena dengan demikian ada yang "hilang" dari kemanfaatan yang terkandung dalam tanah untuk anak cucu generasi penerus bangsa nantinya.

Pada saat bersamaan, keberadaan tanah negara yang telantar dan atau diterlantarkan menjadi tidak produktif jumlahnya semakin meluas. Jika dilihat secara secara de jure tanah-tanah yang saat ini diberikan kuasa oleh negara kepada perusahaan negara (baca : BUMN) dan swasta jumlahnya besar. Dari hak yang

1 Martin Roestamy, Human Basic Need of Housing Supported By Land Bank System, dalam Jurnal Internasional IJASOS- International E-Journal of Advances in Social Sciences, Vol. V Issue 14, Agustus 2019 diberikan tersebut secara de facto dalam jumlah yang tidak sedikit cenderung dibiarkan menganggur dan tidak produktif. Dengan demikian penting untuk meletakan kebijakan dari negara guna pemanfaatan lahan tersebut. Paradigma dan asumsi yang dibangun ialah jika tanah-tanah tersebut dalam keadaan nganggur tidak produktif seyogyanya untuk dikerjasamakan saja atau dimanfaatkan oleh pihak ketiga dengan skema pemanfaatan lahan yang produktif, dengan itu tanah tersebut kembali mempunyai dan memberikan kontribusi terhadap perkonomian masyarakat. ${ }^{2}$

Dewasa ini tanah terlantar di Indonesia bukan merupakan barang baru yang keberadaannya tidak diatur dalam peraturan perundang-undanganan. Katakanlah sejak lahirnya Undang-undang pokok agraria (UUPA) tahun 1960 sudah mengatur bagaimana akibat hukum jika diterlantarkan yaitu status tanah tersebut menjadi terhapuskan hak kepemilikannya. ${ }^{3}$ Sejalan dengan itu, TAP MPR No/ IX/MPR/2001 tentang Pembaharuan Agraria dan Pengelolaan Sumber Daya Alam menyatakan bahwa tidak membenarkan perilaku pemegang hak yang menelantarkan tanahnya, permasalahan tanah terlantar menjadi topik yang penting untuk dikaji pemerintah, agar terwujudnya amanah dari TAP MPR tersebut dalam rangka upaya pembaharuan hukum agraria.

Maka setidaknya ada 3 (tiga) peraturan teknis yang dapat menjalankan amanah dari undang-undang diatasnya tersebut, yaitu melalui pertama Peraturan Pemerintah Nomor 11 Tahun 2010 tentang Penertiban dan Pendayagunaan Tanah Terlantar. Kedua melalui Peraturan

2http://www.google.com/www.kompasiana.com/ar ioneuodia/kewaspadaan-nasional-terhadappemanfaatan-lahan-terlantar-dapatmewujudkan-ketahanan-pangan diakses pada tanggal 21 April 2020

3 Lihat UUPA di Pasal 27 huruf a angka 3 untuk Hak Milik, Pasal 34 huruf e untuk Hak Guna Usaha, dan Pasal 40 huruf e untuk Hak Guna Bangunan 
Pemerintah Nomor 86 Tahun 2018 tentang Reforma Agraria. Dan ketiga melalui Keputusan BPN Nomor 4 Tahun 2010 tentang Tata Cara Penertiban Tanah terlantar. Ketiganya hadir untuk memberikan pegangan dan pedoman kepada pemerintah, agar dapat menyisir tanah-tanah potensial dari pemberian negara yang tidak diusahakan oleh pemegang hak. Oleh karena itu dengan adanya peraturan diatas diharapkan dapat menata kembali perwujudan tanah sebagai sumber kesejahteraan masyarakat. Dari optimalisasi pengusahaan, penggunaan dan pemanfaatan tanah di seluruh Indonesia, maka dampaknya ialah kepada kualitas lingkungan hidup juga, selain itu dapat mengurangi kemiskinan, menciptakan lapangan kerja dan meningkatkan ketahanan pangan dan energi. ${ }^{4}$

Yang akan menjadi topik utama penelitian ini ialah dari beberapa bangunan yang berdiri di kawasan puncak seperti villa, bangunan ruko, sekolah, bahkan pondok pesantren dan juga lahan pertanian disekitarnya yang berada di atas tanah penguasaan PT. Perkebunan Nusantara VIII (PTPN VIII) Gunung Mas pada umumnya tidak mengetahui bahwa status tanah yang mereka tempati itu berada dalam sertifikat HGU-nya PTPN VIII. Mereka membeli lahan tersebut melalui para penggarap dengan perantara biong (makelar) tanah yang berani bermain tanah. Para makelar tersebut memberikan info atas tanah yang mereka tawarkan ialah dalam status eks alias bekas tanah guna usaha perusahaan, dan di iming-imingi bisa menjadi sertifikat hak milik tanah tersebut.

Hal tersebut tentunya sangat merugikan pembeli yang tidak tahu dengan adanya peran biong dalam penjualan lahan tersebut. Hasilnya ialah pembeli bertemu dengan sengketa saling klaim kepemilikan tanah garapan, bahkan pembeli dapat berurusan dengan pihak PTPN VIII secara langsung.

4 Lihat di penjelasan PP No. 11 Tahun 2010 tentang Penertiban dan Pendayagunaan Tanah Terlantar
Terdapat data yang penulis temukan tidak sinkron dengan yang dimiliki oleh internal PTPN VIII, yang mana pada tahun 2011 PTPN mencatat bahwa dari 1.623,18 $\mathrm{Ha}^{5}$ lahan HGU milik PTPN VIII sekitar 382 $\mathrm{Ha}^{6}$ lahan tersebut terokupasi. ${ }^{7}$ Sedangkan media elektronik Radar Bogor mencatat bahwa lahan yang beralih fungsi di tahun 2017 sebanyak 700 Ha. ${ }^{8}$ Ini menandakan bahwa data internal dan eksternal sudah tidak uptodate lagi, sedangkan PTPN sepertinya masih memegang data yang hilang hanya $382 \mathrm{Ha}$.

Dengan melihat kondisi tersebut maka penulis tertarik untuk melakukan penelitian lebih lanjut tentang kondisi tanah yang beralih fungsi misal jadi pondok pesantren dan tanah terlantar lainnya supaya bisa dimanfaatkan menggunakan asas kemanfaatan hukum.

Sehingga berdasarkan uraian diatas maka penulis merumuskan kedalam penelitian tesis yang bermuara dari kegiatan pengabdian kepada masyarakat yang berjudul : "Model Pemanfaatan Atas Tanah Terlantar dai Hak Guna Usaha (HGU) PT. Perkebunan Nusantara VIII dikaitkan dengan Pengembangan Usaha Pondok Pesantren di Kawasan Bopunjur" dengan dua identifikasi masalah sebagai berikut :

1. Bagaimana konsep dan politik enclaving tanah terlantar ex Hak Guna Usaha (HGU) di Indonesia saat ini ?

2. Bagaimana pengembangan model enclaving atas tanah terlantar ex Hak Guna Usaha (HGU) PT. Perkebunan Nusantara untuk pengembangan usaha

5 Data didapat dari hasil Wawancara dengan bagian verifikasi PTPN VIII Gunung Mas Pak Toni di kantor pusat kebun Gunung Mas Puncak Cisarua

6 Data didapat dari penuturan Kabag Optimalisasi Asset PTPN VII yaitu Pak Yani di Kantor Pusat PTPN VIII Gunung Mas

7 Okupasi adalah istilah yang digunakan oleh PTPN VIII untuk menyebut para penggarap tanah HGU-nya PTPN VIII

8 Aan Suryana Petugas Pendataan Lahan PTPN VIII Gunung Mas 700 hektare lahan hilang, http://www.google.com/amp/s/www.radarbogor id/201712/29/700-hektare-lahan-hilang/amp/ diakses pada tanggal 27 Januari 2020 
pondok pesantren di Kawasan Bopunjur?

\section{METODE PENELITIAN}

Metode penelitian yang digunakan untuk penelitian ini yaitu dengan menggunakan analisis yuridis normatif dengan pendekatan kualitatif mengkombinasikan bahan hukum sekunder dengan bahan hukum primer sehingga menghasilkan analisis fakta yang terjadi dilapangan sekaligus melaksanakannya Focus Group Discussion yang mana adalah satu kesatuan kegiatan pengabdian kepada masyarakat dengan pihak terkait yaitu PTPN VIII langsung, para kyai pondok dan masyarakat tani,

Teknik pengumpulan data yang dilakukan dengan cara penelitian kepustakaan dengan mencari dan mengumpulkan serta meneliti bahan pustaka yang merukan bahan sekunder. Dari data sekunder tersebut dikombinasikan dengan fakta-fakta yang ada dilapangan serta keterangan para pihak yang terkait.

Adapun yang menjadi bahan pengumpulan data ialah sebagai berikut.

1. Bahan hukum primer seperti peraturan-peraturan perundangundangan yang terkait dengan tanah terlantar hak guna usaha dan pemanfaatannya

2. Bahan hukum sekunder yaitu kepustakaan tentang cara enclaving atas tanah negara dan tanah terlantar lainnya, dapat juga dilihat dari hasil penelitian atau artikel jurnal yang berkaitan, dari itu maka dikombinasikan antara data sekunder dengan data primer.

Dan penelitian ini diolah menggunakan analisis data yang berupa analisis kualitatif dengan mengkaji sekaligus menguraikan sumber-sumber data dengan menggunakan deskripsi tiga tahapan yaitu pertama mengumpulkan data primer, sekunder dan tersier. Setelah itu tahap kedua penyajian, penelaahan dan pengolahan data. Yang terakhir yaitu menarik kesimpulan dengan metode deduktif - induktif..

\section{PEMBAHASAN}

\section{A. KONSEP DAN POLITIK ENCLAVING ATAS TANAH EX PERKEBUNAN DAN PERTANIAN DI KAWASAN BOPUNJUR}

Pada zaman kolonial Belanda di Indonesia, kurang lebih sekitar 1.150.000 $\mathrm{Ha}$ tanah partikelir yang tersebar dibeberapa daerah terutama di Jawa Barat. Tanah partikelir menurut fungsi dan pemiliknya dapat dibedakan menjadi tiga jenis yaitu tanah partikelir orang timur asing (tanah Tionghoa), tanah partikelir oleh rakyat asli (tanah usaha) dan tanah partikelir oleh tuan tanah (tanah kongsi) yang dahulu biasa digunakan untuk disewakan semacam tempat tinggal bagi penduduk yang ingin tinggal di tanah partikelir tersebut. ${ }^{9}$

Bermuara dari badan usaha yang dibentuk pemerintah Belanda pada tahun 1935 yang bertugas menangani pengembalian tanah partikelir bernama N.V Javansche Particuliere Landrijen Maatschappij. Barulah setelah Indonesia merdeka tepatnya pada tahun 1948, dibentuk panitia Indonesia untuk memberikan usulan kepada pemerintah terkait cara untuk mengambil alih tanah partikelir menjadi tanah negara yang tersisa sejak zaman kolonial.

Selanjutnya Pemerintah mengeluarkan suatu keputusan nomor 1 tanggal 8 April 1949 yang menuntut pengembalian tanah partikelir dan kepastian hukum kerja panitia yang telah dibentuk. Dari keputusan pemerintah tersebut didapatilah pengembalian tanah partikelir sekitar 400 $\mathrm{Ha}^{10}$ yang terletak di bagian utara Bogor dan membeli tanah yang dikuasai oleh $N V$.

\footnotetext{
9 Supriyadi, Hukum Agraria, cetakan ke-5, Sinar Grafika, Jakarta, 2012, Hlm. 20

10 Diskusi tentang pelaksanaan enclav PT. Cisarua Selatan dengan Pak Sudri Heryana selaku mantan pegawai BPN yang menangani enclav atas tanah PT. Cisarua Selatan.
} 
Culture Maarschappij Tjisarua Zuid yang dikenal dengan PT. Cisarua Selatan. Usaha untuk mengambilalih (baca : melikuidasi) tanah-tanah partikelir yang dilakukan pemerintah Indonesia menemui beberapa kendala selain kendala ketersediaan kas negara diawal masa kemerdekaan.

Kendala lainnya ada pula sikap tuan tanah yang tidak mau melepaskan tanah partikelir dengan harga yang murah, kedua faktor itu menjadi penghambat dalam proses pengembalian. Selanjutnya pemerintah Indonesia akhirnya membentuk Undang-undang Nomor 1 Tahun 1958 tentang Penghapusan TanahTanah Partikelir beserta aturan pelaksananya yaitu melalui Peraturan Pemerintah Nomor 18 Tahun 1958 untuk mengukuhkan langkah pemerintah dalam rangka penghapusan tanah-tanah partikelir di Indonesia. Dengan terbitnya undangundang tersebut hak-hak pertuanan yang melekat terhapus dan tanah bekas partikelir secara hukum menjadi tanah negara. ${ }^{11}$

PT. Cisarua Selatan yang luas lahannya kurang lebih $400 \mathrm{Ha}$ itu otomatis menjadi tanah negara. Pada perjalanannya, terdapat perubahan penguasaan atas tanah yang berdiri di eigendom-nya PT. Cisarua Selatan, ada yang lahannya diberikan kepada karyawannya, ada pula yang sudah dikuasai oleh masyarakat lain sampai dengan saat ini kondisinya menjadi Pasar (Pasar Cisarua). Dari luas lahan terdapat dua konsep penguasaan, yang pertama ada yang disebut tanah kongsi (tanah negara) dan yang kedua disebut tanah usaha. Tanah kongsi/tanah negara merupakan tanah yang dikuasai langsung oleh tuan tanah/ pemilik tanah dan apabila diatasnya terdapat usaha atau perumahan rakyat dikenakan konsep sewa menyewa bagi masyarakat yang tinggal dibidang tanah tersebut, sedangkan tanah usaha adalah tanah yang tidak dikuasai secara langsung oleh tuan tanah melainkan merupakan tanah desa atau milik masyarakat adat

11 Urip Santoso, Hukum Agraria dan Hak-hak Atas Tanah, Kencana, Jakarta, 2012, Hlm. 28 diatasnya terdapat hak penduduk bersifat turun temurun. ${ }^{12}$ Dalam hal ini jika ingin ditingkatkan menjadi hak milik maka proses permohonannya ialah dengan melalui proses tanah adat kepada kepala adat/ suku atau kepala desa.

Pemerintah melalui program landreform mengambil alih status tanah PT. Cisarua Selatan menjadi tanah negara semata-mata bukan untuk dibagi-bagi secara percuma, ada tujuan yang ingin dicapai dengan program tadi, sebetulnya dengan kondisi puncak sebagai $0 \mathrm{~km}$ Sungai Ciliwung mengharuskan daerah puncak menjadi kawasan konservasi yang kaya akan tanaman penyangganya, oleh karena itu tanah seluas 400 Ha tidak semuanya diberikan untuk kepentingan masyarakat secara konsumtif melainkan diberikan pula kepada para petani untuk bisa mengolah tanah tersebut agar terdapat konservasinya.

Akan tetapi, keinginan tersebut sulit untuk dikerjakan dengan perkembangan pesat masyarakat puncak, saat ini sudah banyak bangunan-bangunan yang berdiri sampai kepada akses yang sekarang sudah menjadi pasar.

Namun masyarakat masih bisa meminta permohonan hak dengan dua tata cara diatas, jika untuk keperluan konsumtif untuk berdirinya hunian (bangunan) maka permohonan dapat diajukan kepada BPN melalui skema jual beli atau penggantian uang kas negara. Permohonan hak ada syarat yang harus dipenuhi yaitu :

1. Boleh non-pertanian

2. Menunjukan kartu tanda penduduk yang tidak harus warga sekitar lahan

3. Diperbolehkan untuk atau merencanakan pembangunan fisik

4. Adanya pembayaran kas kepada negara sebagai pembelian tanah partikelir dan dimohonkan dikeluarkan sertifikat oleh BPN Provinsi

Dan yang kedua permohonan tanahtanah tersebut murni untuk kegiatan pertanian dan perkebunan melalui

12 Boedi Harsono, Hukum Agraria Indonesia, Djambatan, Jakarta, 1994, Hlm. 99 
program landreform. Pada permohonan ini pemohon menyiapkan syarat sebagai berikut :

1. Pemohon adalah warga sekitar lahan

2. Oleh karena itu rumahnya harus dekat dengan lokasi lahan

3. Peruntukannya harus guna pertanian dan perkebunan

4. Tidak boleh berdiri bangunan (fisik)

5. Kartu tanda penduduk menunjukan pekerjaannya sebagai petani

6. Tidak ada ganti rugi untuk negara

Dengan demikian pada bagian konsep enclaving disini mempunyai alur bahwa yang pertama tanah tersebut yang berawal dari eigendom verponding sebuah perusahaan harus terlebih dahulu diambil alih oleh negara sebagai tanah negara. Setelah itu pemilik tanah sebelumnya dapat memohonkan objek tanah yang dikuasai kepada negara untuk dapat dikonversi, apakah akan menjadi objek landreform atau menjadi konsumsi pemohon berupa hunian.

\section{B. PENGEMBANGAN MODEL ENCLAVING ATAS TANAH TERLANTAR EX HAK GUNA USAHA (HGU) PT. PERKEBUNAN NUSANTARA VIII UNTUK PENGEMBANGAN USAHA PONDOK PESANTREN DI KAWASAN BOPUNJUR}

Tanah HGU PTPN VIII sangatlah luas, meliputi wilayah Jabar sampai dengan memiliki juga di wilayah Banten. Di kebun gunung mas sendiri HGU PTPN VIII seluas $1.623,18 \mathrm{Ha}$ dengan rincian sebagai berikut

\begin{tabular}{|c|c|c|c|}
\hline NO. & APDELING & $\begin{array}{l}\text { LUAS } \\
\text { (HA) }\end{array}$ & $\begin{array}{l}\text { CAKUPAN } \\
\text { WILAYAH }\end{array}$ \\
\hline 1 & $\begin{array}{l}\text { Gunung } \\
\text { Mas } 1\end{array}$ & 462,75 & $\begin{array}{l}\text { Tugu Selatan } \\
\text { (Kecamatan } \\
\text { Cisarua) }\end{array}$ \\
\hline 2 & $\begin{array}{l}\text { Gunung } \\
\text { Mas } 2\end{array}$ & 419,20 & $\begin{array}{l}\text { Tugu Selatan } \\
\text { (Kecamatan } \\
\text { Cisarua) }\end{array}$ \\
\hline 3 & $\begin{array}{l}\text { Cikopo } \\
\text { Selatan }\end{array}$ & 741,23 & 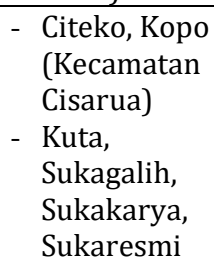 \\
\hline
\end{tabular}

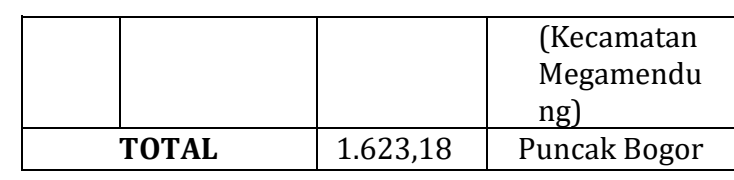

Tabel 1.

Cakupan Luasan HGU PTPN VIII kebun Gunung Mas

Yang oleh negara diberikan hak usaha diatas tanah tersebut dengan komoditas perkebunan teh. Namun pada kenyataannya dari gunung mas sampai daerah Pasir Muncang sudah banyak tanahtanah beralih fungsi. Khususnya dari pemantauan setidaknya ada tiga pondok pesantren yang berdiri di atas tanah HGU tersebut. Yaitu Al-Musthafawiyah (Pasir Muncang), Markaz Syariah (Kuta) dan Wadi Mubarak (Kuta). Merupakan pondokpondok yang berdiri diatas HGU-nya PTPN VIII.

Bisa dilihat juga betapa luasnya HGU PTPN melihat peta sebagai berikut :

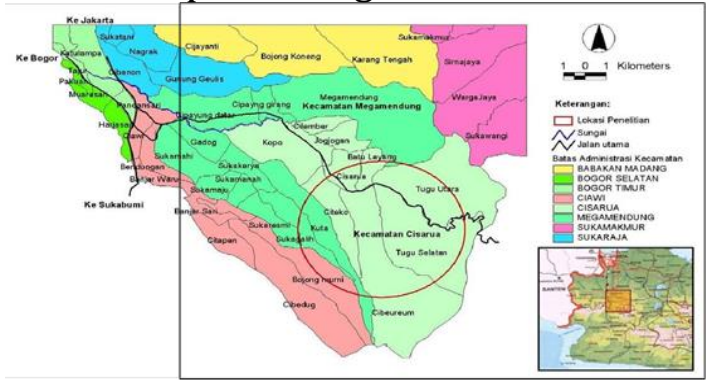

Gambar 1.

Posisi Kebun Gunung Mas (lingkaran)

Dengan peta luasan sebagaimana teruraikan dan tergambarkan diatas, seyogyanya PTPN VIII menjadi perusahaan yang memiliki benefit yang tinggi, karena potensi tanah di sekitar puncak sangatlah potensial menjadi lumbung ekonomi untuk negara. Menyadari bahwa peran PTPN VIII sebagai perusahaan negara tentunya tidak sekedar profit center yang dituju, tetapi juga adanya tujuan menjadi agent of development $^{13}$ sehingga kehadirannya semata-mata untuk peningkatan kesejahteraan masyarakat melalui usahanya.

13 agent of development adalah lembaga yang memobilisasi dana utuk pembangunan ekonomi di suatu wilayah. 
Tidak dapat dipungkiri bahwa seyogyanya perlakuan PTPN VIII terhadap tanah HGU yang diberikan oleh negara bermakna bukan untuk dimiliki perusahaan, melainkan untuk diusahakan oleh perusahaan. Yang memiliki tetaplah berada dalam kuasa negara.

Eigendom verponding sudah turun temurun dari masa zaman kolonial Belanda yang mana dilakukan nasionalisasi kata yang terkenal dengan sebutan nommen verclaring yaitu pernyataan dari pada meninjau semua tanah yang digunakan untuk pertanian (verponding) melalui Hak Guna Usaha, yang disebut juga dengan hak erfact lalu di nasionalisasi menjadi Hak Guna Usaha.

Lahan yang merupakan aset negara dan diberikan kewenangan juga daerah mengelola untuk pemanfaatan, pemberdayaan, pembebasan lahan untuk pembangunan produktif. Mengharuskan daerah dapat memaksimalkan itu semua. PTPN VIII dapat mengembangkan sektor sumber tanah dari CSR perusahaan untuk lembaga nonformal seperti pondok pesantren, tentunya dengan skema kerjasama lahan dengan PTPN VIII selaku pemegang HGU. 14

Ketika sumber daya berupa lahan dikelola dengan baik oleh suatu instansi/badan hukum yang legal, maka kedepannya akan menjadi model untuk program pemberdayaan pondok pesantren, daerah sebagai pemegang aset bisa mengoptimalkan hak menguasai negaranya.

Dengan konsep dan politik enclaving yang telah di paparkan pada bagian 1 maka penulis mengembangkannya dengan alur prosedur sebagai berikut:

Pertama, katakanlah fokus kepada 385 Ha lahan PTPN yang telah hilang/beralih fungsinya yang tadinya kebun teh menjadi pemukiman, ada sekolah, pondok pesantren, pengembangan usahanya, selebihnya digunakan lahan pertanian masyarakat penggarap sekitar kebun.

14 Martin Roestamy, Human Basic Need of Housing Supported By Land Bank System, Loc, Cit., Hlm 981
Dalam aturan yang telah dibahas diatas maka secara otomatis lahan tersebut sudah dapat dikategorikan sebagai objek enclaving oleh negara melalui panitia A BPN Kabupaten.

Kedua, data 700 Ha yang hilang menurut keterangan pers kompas menandakan bahwa terhadap penggarapan tanah HGU PTPN ada yang telah berstatus eks (tidak diusahakan) karena objek lahan tersebut terus menerus sudah masyarakat kuasai ini pun sudah bisa dikatakan sebagai objek enclaving untuk program redistribusi tanah bagi petani.

Ketiga, berbicara tentang pemanfaatan tanah oleh pondok pesantren untuk pengembangan usahanya telah ada setidaknya 3 contoh yang dapat di terapkan menjadi model, yaitu 1) pondok Musthafawiyah dengan luasan 30 Ha untuk kebun salaknya bertujuan sebagai usaha pondok gunak kesejahteraan santri dan para asatidz. 2) Markaz Syariah dengan usaha kebun Alpukat seluas 30 Ha guna kesejahteraan masyarakat sekitar menjadi petani dan operasional pondok dan 3) Bina Tauhid dengan Camping Ground Taman Tahfidz Citeko seluas 6 Ha guna pemberdayaan masyarakat tani disekitar kebun supaya dapat mengisi pengetahuan tani berbasis keagamaan disana, selain itu dapat juga menjadi sarana pelatihan dan pendidikan spiritual bagi santri dan tentunya masyarakat pada umumnya. Ketiganya ada model bagaimana pemanfaatan tanah yang selama ini telah digarap oleh masyarakat pada istilahnya PTPN tidak menghasilkan apapun pada luasan tanah tersebut. Tapi jika akhirnya di buat kerjasama maka perusahaan mendapat income setidaknya membantu perusahaan dalam membayar pajak kepada negara.

Keempat, tentu dengan proses yang bisa dilaksanakan yaitu tahap awal penetapan bahwa perusahaan sudah tidak sanggup lagi untuk mengambil alih lahan okupasi, dari keterangan tersebut pemerintah melalui BPN tidak harus menunggu masa waktu HGU tersebut 
diperpanjang karena amanat dari Perpres Reforma Agraria mengatakan jika tidak diusahakan dan menjadi objek lain maka sudah menjadi syarat tanah HGU sudah bisa kembali menjadi tanah negara. Dari status tanah negara sama dengan proses PT. Cisarua Selatan, karena ada yang menempati sebagai hunian, pondok pesantren, dan lahan pertanian dan perkebunan, di lakukannya penyisiran atau tidak keluar surat edaran Bupati untuk bisa menyisir tanah-tanah HGU yang sudah beralih fungsi.

Kelima, masyarakat dan pondok pesantren yang telah menguasai lahan dapat mengajukan permohonan hak, jika lahan untuk pertanian, memohon hak redistirbusi tanah, jika untuk hunian bisa dengan ganti rugi kepada BPN Provinsi. Setelah itu memohon konversi jika ternyata lahan HGU tersebut sudah dinyatakan dicabut oleh negara melalui Bupati dan Gubernur untuk wilayah Bopunjur.

\section{KESIMPULAN}

1. Melalui konsep politik hukum enclaving atas tanah terlantar awalnya adalah untuk menjamin terwujudnya keadilan dan kemanfaatan tanah secara maksimal. Untuk mewujudkan tujuan tersebut, dari hukum tanah nasional UUPA telah mengatur tentang prinsip tanah yang harus memberikan kemanfaatan sebesar-besarnya untuk kemakmuran rakyat. Dari sana lahir gerakan ekonomi, industri, dan bidang lain dari pemanfaatan tanah tersebut. Pada saat ini melalui Peraturan Pemerintah Nomor 86 Tahun 2018 tentang Reforma Agraria menuntun para pelaksana birokrasi pertanahan bisa mengambil langkah pasti untuk dapat menata kembali struktur penguasaan, pemilikan, penggunaan dan pemanfaatan tanah yang lebih berkeadilan.

2. PTPN VIII adalah perusahaan negara yang oleh negara diberikan penguasaan tanah untuk mereka usahakan, bukan berarti kepemilikan tersebut menjadi hak milik bagi perusahaan. Dari dasar tersebut tidak dibenarkan bila tanah-tanah yang selama ini diberikan oleh negara harus terlantar apalagi menjadi permainan segelintir oknum biong yang justru merugikan perusahaan itu sendiri. Oleh karena itu untuk meminimalisir konflik pertanahan yang saat ini masih berjalan, perusahaan harus dengan sukarela menggalang lembaga-lembaga yang ingin mengamankan lahan mereka dari permainan para biong tersebut. Jika ini dilakukan maka kondisi aman dan tanah negara tidak dimanfaatkan untuk kepentingan individu saja. Jika memang hari ini perusahaan sudah tidak sanggup lagi untuk mengusahakan luasan lahan yang diberikan justru setiap hari hilang, eigendom verponding yang sudah beralih penguasaannya bisa diminta kerjasama dengan perusahaan dengan kontribusi yang nantinya akan didapat kedua pihak. Selebihnya jika dilihat kalau memang benar adanya tanah terlantar atau tanah yang sudah beralih atas nama HGU PTPN VIII maka rugi sekali untuk perusahaan karena setiap tahun dari luasan tanah tersebut harus dibayar ke negara seperti pembayaran PPN dan PBB, jika di enclaving atau dengan konsep kerjasama maka beban itu menjadi ringan bagi perusahaan dan bermanfaat bagi lembaga-lembaga yang ingin lebih memanfaatkan tanah tersebut.

\section{SARAN}

1. Pemerintah melalui Badan Pertanahan Negara (BPN) sudah diberikan wewenang melalui surat edaran kepala bpn tentang pelaksanaan landreform untuk mendata tanah yang potensial menjadi objek landreform. Sehubungan dengan itu harus ada peran yang bersifat proaktif terhadap pendataan 
tanah terlantar di wilayah Bopunjur jangan fokus kepada yang sudah berdiri bangunan saja. Dan menjadi fasilitator distribusi tanah untuk rakyat karena potensi tanah di kawasan Bopunjur sangat besar dan rawan sekali di salahgunakan oleh oknum biong

2. Pemanfaatan tanah untuk pengembangan usaha pondok sudah ada modelnya oleh 3 pondok yang dibahas pada bab IV, kedepannya saran untuk PTPN agar lebih mempermudah jalan bagi pondok untuk bisa melakukan kerjasama strategis, bahkan pondok pesantren bisa menjadi mitra yang baik untuk perusahaan dalam pengamanan lahan dari para oknum biong. Maka dari itu penting untuk menyamakan persepsi di lingkup intern PTPN sendiri agar bisa lebih memperhatikan pondok pesantren di kawasan lahannya.

\section{DAFTAR PUSTAKA}

Boedi Harsono. Hukum Agraria Indonesia (Sejarah Pembentukan UUPA, Isi dan Pelaksanaannya). Jakarta : Djambatan. 1994.

Martin Roestamy, Human Basic Need of Housing Supported By Land Bank System, dalam Jurnal Internasional IJASOS- International E-Journal of Advances in Social Sciences. Vol. V Issue 14. Agustus 2019

Supriyadi. Hukum Agraria, (cetakan ke-5). Jakarta : Sinar Grafika. 2012.

Urip Santoso. Hukum Agraria Kajian Komprehensif. Jakarta : Kencana. 2012.

700 hektare lahan hilang, http://www.google.com/amp/s/www.radarbogor.id/201712/29/700-hektarelahan-hilang/amp/ tahun 2017

Undang-Undang Nomor 5 Tahun 1960 tentang Pokok-Pokok Agraria

Peraturan Pemerintah Nomor 40 Tahun 1996 tentang Hak Guna Usaha, Hak Guna Bangunan dan Hak Guna Pakai Atas Tanah

Peraturan Pemerintah Nomor 11 Tahun 2010 Tentang Penertiban dan Pendayagunaan Tanah Terlantar

Peraturan Presiden Nomor 86 Tahun 2018 tentang Reforma Agraria 